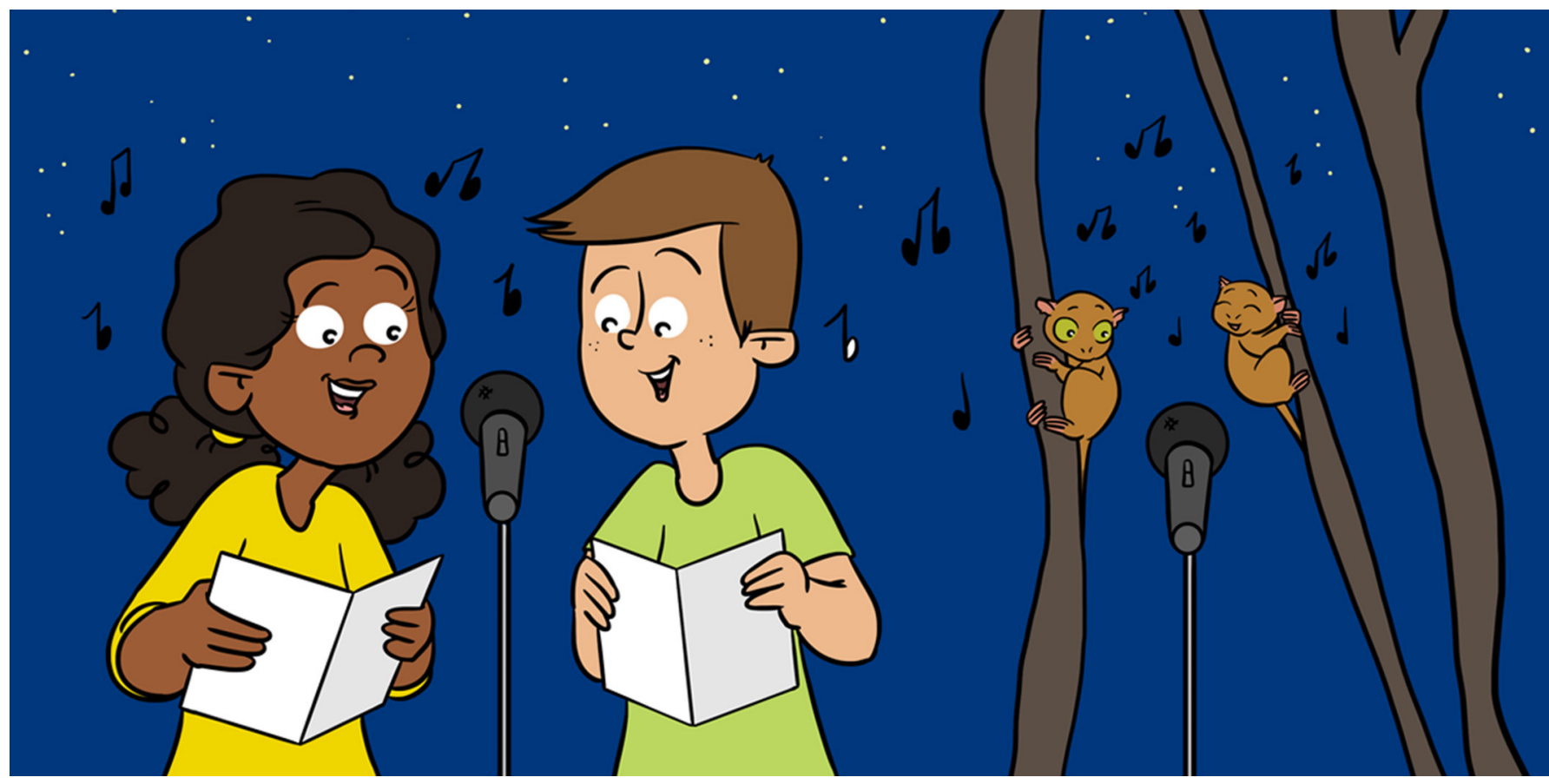

\title{
WHAT STUDYING THE SONGS OF A DISTANT PRIMATE RELATIVE CAN TEACH US ABOUT OURSELVES
}

\section{Dena Jane Clink *}

K. Lisa Yang Center for Conservation Bioacoustics, Cornell Lab of Ornithology, Cornell University, Ithaca, NY, United States

YOUNG REVIEWER:

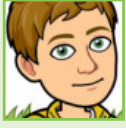

ADAM

AGE: 15
Tarsiers are nocturnal animals. They have eyes that are heavier than their brains. They eat only insects and other living things. Tarsiers are primates, just like humans. And some species of tarsiers sing! Tarsier songs and human language are different in many ways. But if we study the similarities, it may help us better understand human language. In our study, we recorded singing tarsiers on the Indonesian island of Sulawesi. With the help of computers, we found that we could tell individual tarsiers apart based on their songs. Being able to recognize who is singing from far away may be an important function of tarsier songs. We also found that if a female speeds up her song, then the male speeds up his song, too. The ability to modify vocal output based on what others are doing is a universal in human language. Our results show that tarsiers (like humans) can change their vocalizations based on what their partner is doing. The fact that tarsiers and humans are both able to do this indicates that their common ancestor probably had this ability. Our results add support to the idea that 
Figure 1

A tarsier in Tangkoko National Park, North Sulawesi, Indonesia (Photo credit: DC).

PRIMATE

A group of mammals that includes lemurs, lorises, tarsiers, monkeys, and apes (including humans).

\section{TRAITS}

Distinguishing qualities or characteristics.

\section{NOCTURNAL}

Active at night.

\section{FAUNIVOROUS}

An adjective that describes animals that eat other animals.

\section{DUET}

A vocal interaction between two individuals.

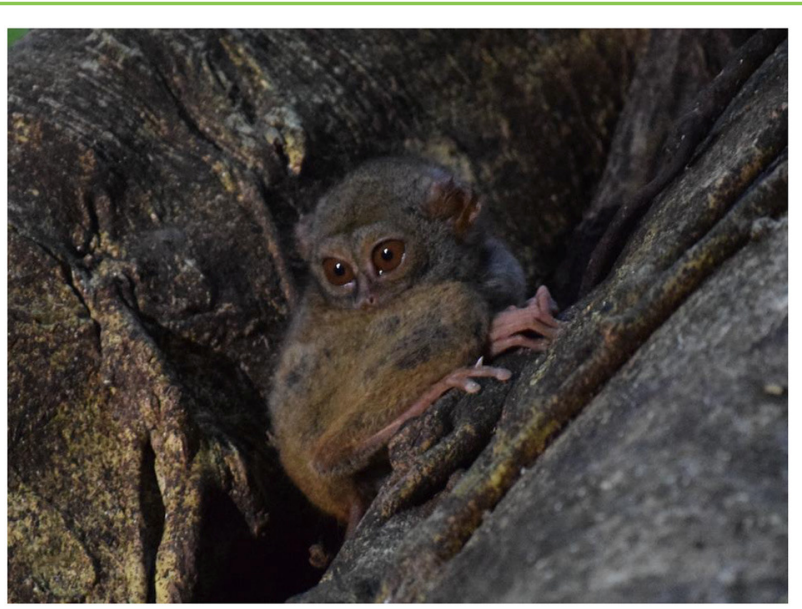

Figure 1

\section{flexibility in vocal interactions evolved long before the appearance of modern humans.}

\section{WHAT IS A TARSIER?}

Tarsiers are primates, just like humans, but they have some pretty amazing traits that are very different from us. They are nocturnal, which means they are active at night. They have enormous eyes that help them see better in the dark (Figure 1). Tarsiers are the only primates in the world that are completely faunivorous, which means they eat only insects and other animals. Humans shared a common ancestor with tarsiers about 55 million years ago [1]. Most primates that are active during the day live in groups, but many nocturnal primates live alone. This is true for most tarsiers, except for the tarsiers found on the Indonesian island of Sulawesi. In Sulawesi, male and female tarsiers live in pairs with their offspring. This contrasts with the tarsiers found on Borneo and in the Philippines, which live alone. This difference in social structure may be related to the number of insects that live the in the forests: the forests of Sulawesi have a higher abundance of insects, which may allow tarsiers to live in larger groups.

The tarsiers on Sulawesi also have another unique trait: the males and females sing together [2]! We also call tarsier songs duets because the males and females coordinate and alternate their singing. Sometimes the juveniles will sing along with their parents, and in this case we call the song a chorus. There are many primates (over 500 species), but only a few of them sing. The singing primates include tarsiers, indris, titi monkeys, gibbons, and humans. Singing primates tend to live in small groups with just the adult male, adult female, and their offspring. They also tend to be territorial, which means they do not share their home range with other groups. Tarsiers on Sulawesi sing at dawn as they return to their sleeping trees. We think tarsier song has two functions: (1) to reunite group members after the night; and (2) to communicate 


\section{COMMON}

ANCESTOR

A concept in evolutionary biology where one species is an ancestor of two or more species that lived later in time.

\section{VOCAL FLEXIBILITY}

The ability to change the structure or use of vocalizations based on different social or environmental contexts.

\section{EVOLUTIONARY}

\section{HISTORY}

A description of how extinct and living species evolved over time. with their neighbors [2]. Scientists still do not understand why certain species of primates sing and others do not, but maybe one day you can help us figure it out!

\section{WHAT CAN STUDYING TARSIERS TEACH US ABOUT HUMANS AND HUMAN SPEECH?}

Humans can read, write, and speak about complex ideas. These abilities make us unique among animals. Scientists have been working for a long time to understand how these abilities came to be. One way that scientists can study this is by comparing humans to other animals. For example, if we find a shared trait in humans and a distant primate relative, this means that the trait was probably present in their common ancestor. If a trait is seen only in humans, and not a distantly related primate, then we assume that this trait was not present in the common ancestor. Such studies can help us understand which traits are new in humans, and this could give us clues about how unique human abilities evolved.

Let us look at the example of speech. People take turns when speaking and tend to not overlap when someone else is talking. People can easily change what they say (and when they say it) depending on the person they are speaking to. These are patterns we see no matter what language people are speaking [3]. Early studies indicated that other primates did not have the same ability to learn sounds and language that humans do. Scientists assumed that primates were not able to change their vocalizations once they became adults. But scientists are now learning that this is not always true. Primates have some of the same abilities as humans, including vocal flexibility and turn-taking. If we see the same abilities in distantly related animals (like humans and tarsiers), this means that the trait evolved far back in evolutionary history.

\section{RECORDING TARSIERS AND LEARNING ABOUT THEIR SONGS}

In our study, we recorded 15 pairs of tarsiers in Tangkoko National Park, Indonesia, using a acoustic recording device and a microphone. Our first goal was to see if we could tell tarsiers apart from each other based on their songs. In humans, if a family member or close friend calls, you can tell immediately who is calling just from the sound of the person's voice. We predicted that this would also be the case for tarsier songs. Our second goal was to test whether tarsier songs have rhythm. Across human cultures, music is an important aspect of everyday life, and almost all humans can dance to a beat. Whether this ability is seen in other animals is still an open question. Our third goal was to see if tarsiers, like humans, can change their songs depending on their partner's song. 
Figure 2

Spectrograms of songs from four different tarsier pairs. In the spectrograms, the $x$-axis represents time and the $y$-axis represents frequency or pitch of the sound.

The colors on the spectrogram represent amplitude (or loudness) at a particular time and frequency.

Green and red represent moderate and high amplitudes, whereas blue represents low amplitudes. In the first spectrogram (A) the male notes are shown with red arrows and the female notes are shown with white arrows. The male notes are very consistent, and the female notes change in frequency and duration. For all four songs, the male and female are singing together. Can you see the differences between male and female notes in the tarsier songs? How about differences between the different tarsier pairs?

Audio 1. Recording of a tarsier pair in Tangkoko National Park, Sulawesi, Indonesia. This recording was used to make spectrogram (A). https://youtu.be/4kw 8vsQR_qM.

Audio 2. Recording of a tarsier pair in Tangkoko National Park, Sulawesi, Indonesia. This recording was used to make spectrogram (B). https://youtu.be/478 o4RuJ6PQ.

Audio 3. Recording of a tarsier pair in Tangkoko National Park, Sulawesi, Indonesia. This recording was used to make spectrogram (C). https://youtu.be/RMlbRge iVrE.
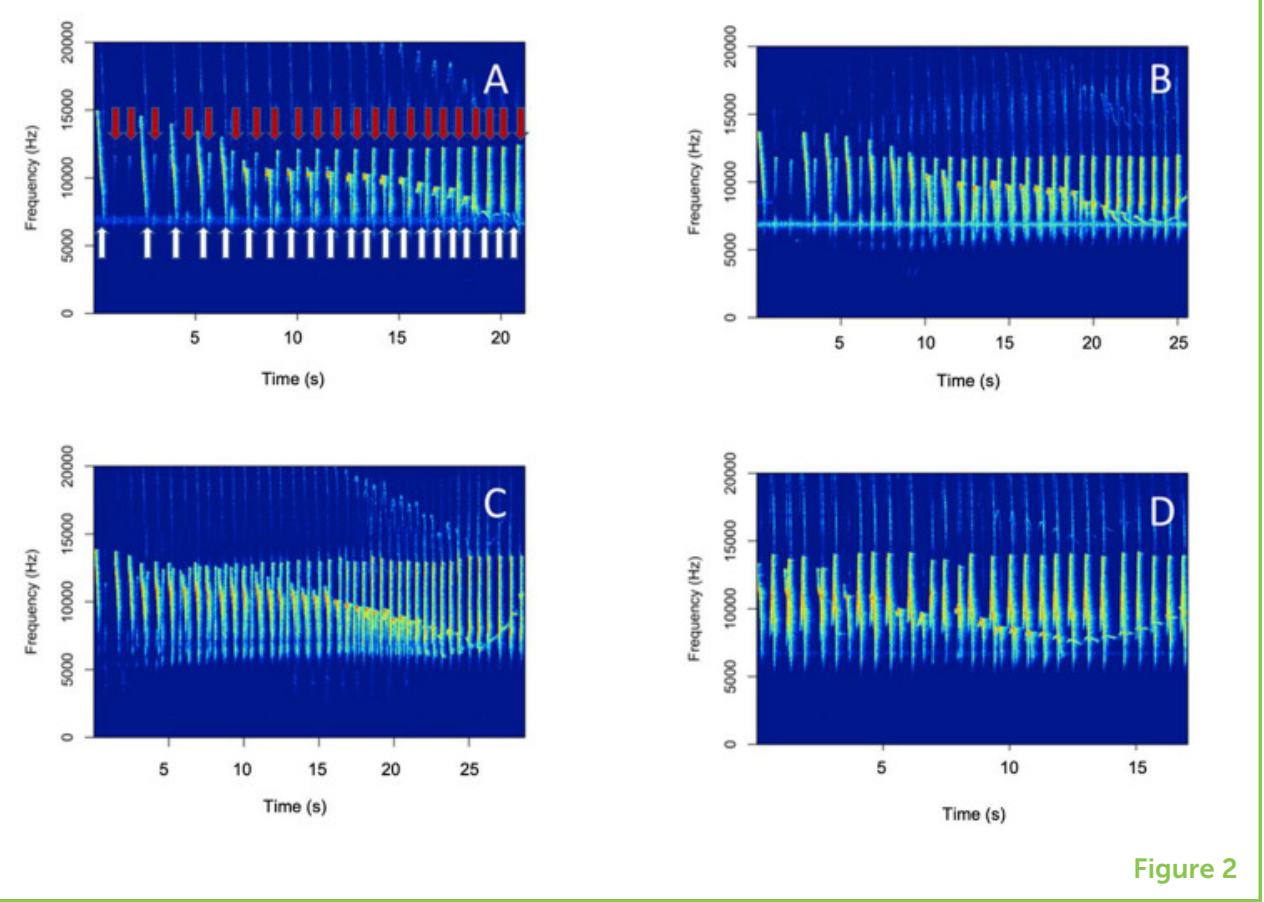

A common way for scientists to study sound is by creating spectrograms, which provide visual representations of sounds. You can see spectrograms of tarsier songs in Figure 2. We made the spectrograms using specialized software [4].

\section{WHAT WE FOUND}

In tarsier songs the male and female parts sound different. After lots of practice, it became easy for us to tell the males and females apart just by listening and looking at the spectrograms. The male notes are pretty consistent, but the female notes get longer and change in frequency (or pitch) over time. Although we can tell the males and females apart, it is more difficult to tell different tarsier individuals or pairs apart from one another based on their songs-we needed the help of computers for that. Testing whether songs contain information about the identity of the individual or pair can help us understand the function of the song. We found that (with the help of computers) we could tell tarsier individuals apart based on their songs. We also found that it was easier to tell females apart from each other than males. We think that one of the functions of the female tarsier songs may be related to recognizing singing animals that are far way. We think this because female songs contain information about the identify of the calling animal.

We also found that tarsier songs have rhythm, but males have more consistent rhythm than females. This is an important finding because all humans have the ability to produce and perceive rhythmic sounds. We also found that, if a female speeds up her song, the male will then speed up his song. This important finding shows that tarsiers, like 
Figure 2

Audio 4. Recording of a tarsier pair in Tangkoko National Park, Sulawesi, Indonesia. This recording was used to make spectrogram (D) https://youtu.be/ DH5UhalxQso

\section{SPECTROGRAM}

A visual representation of sound. The $x$-axis represents time, the $y$-axis represents frequency, and the color corresponds to the strength or loudness of the signal at a particular time and frequency.

\section{AMPLITUDE}

A measure of the height of the sound wave. The amplitude of sound wave determines how loud it is.

FREQUENCY

The number of cycles of a sound wave per second; sometimes referred to as pitch. Humans can generally hear sounds between 20 and $20,000 \mathrm{~Hz}$ humans, can change their song based on how their partner is singing. This ability to change their songs based on how their partners are singing have previously shown in indris and gibbons $[5,6]$. We found this ability also exists in tarsiers. Since tarsiers have both rhythm and the capability to track their partners, our results indicate these abilities arose early in primate evolutionary history, and before the evolution of modern humans.

\section{WE STILL HAVE A LOT TO LEARN}

Individual tarsiers sound different from each other, but does this mean that tarsiers can tell each other apart based on their songs? And how do these song differences come about? Do young tarsiers learn their songs from their parents? If they do, do young tarsiers sound like their parents when they grow up? In many songbirds, those that have lived together longer sing in a more synchronized way. We do not know if this is the case with tarsiers, but it is possible. We hope to do future studies in which we start recording tarsiers when they are young. Studying tarsiers over their lifetimes will help us learn more about how tarsier songs develop. In science, there are always more questions to ask and more things to learn! And we still have much to learn about our tiny primate relatives, the tarsiers.

\section{ORIGINAL SOURCE ARTICLE}

Clink, D. J., Tasirin, J. S., and Klinck, H. 2019. Vocal individuality and rhythm in male and female duet contributions of a nonhuman primate. Curr Zool. 66:173-86. doi: 10.1093/cz/zoz035

\section{REFERENCES}

1. Schmitz, J., Noll, A., Raabe, C. A., Churakov, G., Voss, R., Kiefmann, M., et al. 2016. Genome sequence of the basal haplorrhine primate tarsius syrichta reveals unusual insertions. Nat Commun. 7:12997. doi: 10.1038/ncomms12997

2. MacKinnon, J., and MacKinnon, K. 1980. The behavior of wild spectral tarsiers. Int J Primatol. 1:361-79. doi: 10.1007/bf02692280

3. Stivers, T., Enfield, N. J., Brown, P., Englert, C., Hayashi, M., Heinemann, T., et al. 2009. Universals and cultural variation in turn-taking in conversation. Proc Natl Acad Sci USA. 106:10587-92. doi: 10.1073/pnas.0903616106

4. Barreda, S. 2015. PhonTools: Functions for Phonetics in R. R Packag Version 02-21.

5. Gamba, M., Torti, V., Estienne, V., Randrianarison, R. M., Valente, D., Rovara, P., et al. 2016. The indris have got rhythm! timing and pitch variation of a primate song examined between sexes and age classes. Front Neurosci.

10:249. doi: 10.3389/fnins.2016.00249 
6. Terleph, T. A., Malaivijitnond, S., and Reichard, U. H. 2018. Male white-handed gibbons flexibly time duet contributions. Behav Ecol Sociobiol.

72:16. doi: 10.1007/s00265-017-2432-z

SUBMITTED: 24 June 2020; ACCEPTED: 18 November 2021;

PUBLISHED ONLINE: 16 December 2021.

EDITED BY: Stuart Semple, University of Roehampton London, United Kingdom

CITATION: Clink DJ (2021) What Studying the Songs of a Distant Primate Relative Can Teach Us About Ourselves. Front. Young Minds 9:575984. doi: 10.3389/frym. 2021.575984

CONFLICT OF INTEREST: The author declares that the research was conducted in the absence of any commercial or financial relationships that could be construed as a potential conflict of interest.

COPYRIGHT () 2021 Clink. This is an open-access article distributed under the terms of the Creative Commons Attribution License (CC BY). The use, distribution or reproduction in other forums is permitted, provided the original author(s) and the copyright owner(s) are credited and that the original publication in this journal is cited, in accordance with accepted academic practice. No use, distribution or reproduction is permitted which does not comply with these terms.

\section{YOUNG REVIEWER}

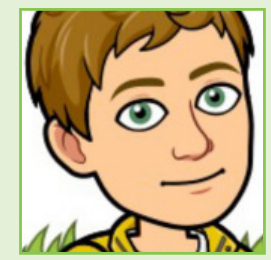

\section{ADAM, AGE: 15}

$\mathrm{Hi}$, my name is Adam. I live with my parents, older brother, dog, fish, and two birds. I am a big fan of Science and History. I like to draw, write, and read, My favorite sport is soccer (or football). I enjoy swimming in the ocean and playing video games.

\section{AUTHOR}

\section{DENA JANE CLINK}

Dena Jane Clink is the lead author on the original tarsier study. She is a research associate in the K. Lisa Yang Center for Conservation Bioacoustics in the Cornell Lab of Ornithology. She is particularly interested in species of primates that sing together, and has done work on tarsiers, titi monkeys, and gibbons. One of her passions is to make science more accessible for all. She also hopes that her work on vocal primates can be used to help improve conservation efforts for these species. When she is not in the jungle recording primates, she can be found hiking in upstate New York with her dog Monito or doing yoga. *dena.clink@acornell.edu 